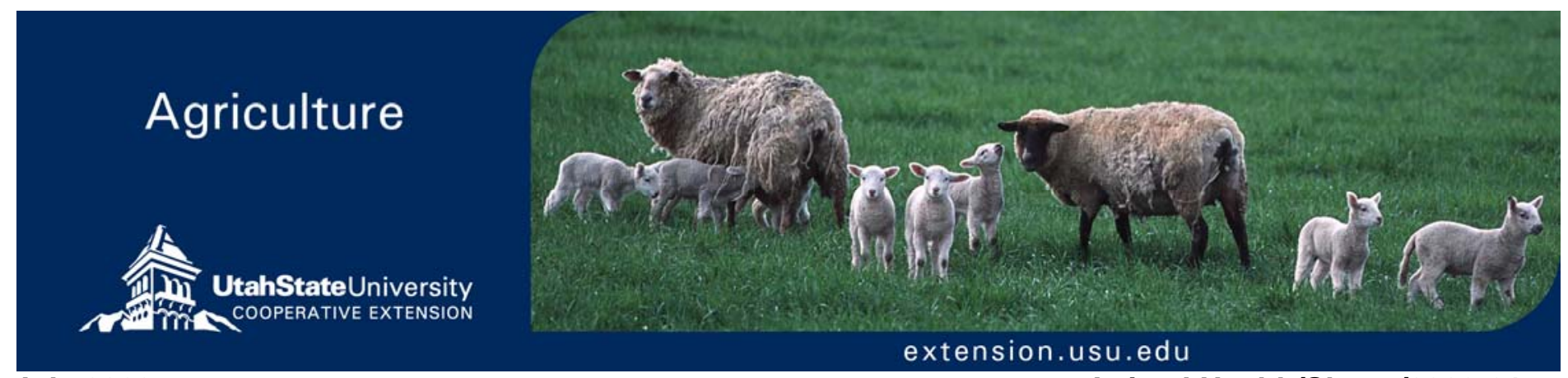

July 2009 Update of AH/Sheep/16, July 1997 by Dr. Clell Bagley

Animal Health/Sheep/2009-01pr

\title{
Prevention of Hydatid Disease
}

\author{
Dr. Kerry A. Rood, Extension Veterinarian \\ Dr. Jane Kelly, Veterinary Laboratory Diagnostician
}

Hydatid disease of man is also called

echinococcosis. The causative agent is the larval stage of a dog tapeworm (Echinococcus granulosus). Though other definitive and intermediate hosts exist, the dog/sheep cycle is the most important as far as disease in man. In the normal life cycle, the adult stage of this tapeworm is very small and difficult to see and resides in the definitive host (carnivore). Dogs are common definitive hosts for this tape worm. Adult tape worms release tiny microscopic eggs which pass into the environment with their feces. Once in the environment (see Figure 1.) the eggs are ingested by an intermediate host. Common intermediate hosts are herbivores. In the case of Echinococcus sp., sheep are normally seen as intermediate hosts along with cattle, goats, deer and mice. The ingested eggs hatch and penetrate the gut wall, enter the blood stream, and are carried to internal organs. Here they set up residence and form cysts. These cysts are full of infective stages called protoscolices. When the intermediate host dies and is eaten by the definitive host (e.g., dog or another canid), these protoscolices evaginate and attach to the intestinal wall, later becoming adults inside the digestive tract. As adults, tape worms release eggs and the life cycle repeats (see Figure 1.)

Man is considered a "dead end" host in this disease because the infection doesn't spread from an infected person to another person, or even to a dog. The intermediate host is sheep, deer, or rodents; where the cysts are formed in them just as in man. However, if dogs are allowed to eat the internal organs of infected intermediate hosts (sheep, cattle, goats, deer, and mice) the dogs become infected and the larval tapeworms develop into adults. That dog begins to shed eggs from its intestinal tract within about 7 weeks and the cycle repeats. Dogs may also be affected by other tapeworms but these are much larger and easily visible. Humans can become very ill should they ingest eggs and they travel to internal organs and become large cysts that interfere with organ function. People are exposed to the infective eggs by petting or grooming dogs and then ingesting the egg through handling food or introducing it into the mouth on the hand.

Parasites, in general, survive by sheer mass of numbers and that is the case with hydatid disease. A heavily infected dog may shed thousands of eggs daily. Only one of these has to get from the tail hair to the dog muzzle, to a person's hand, to mouth to result in hydatid disease for that person.

Central Utah (Sanpete County) was identified in the early 1970s as being persistently infected with this tapeworm, in both the sheep and dogs. Control efforts have reduced the incidence of hydatid disease in Sanpete County but have not eradicated it. Periodical cases of hydatid disease in small ruminants (see Figures 2 and 3 ) are diagnosed in Utah's veterinary diagnostic laboratory. People in other areas of Utah should not feel they are without any danger. Sheep and dogs from Sanpete have been transported to all parts of the state and it is likely that the Echinococcus 
tapeworm has gone along for the ride. It just needs the right circumstance and time to show its effect.

Echinococcosis is a substantial cause of death in many parts of the world. Humans may develop aggressive and damaging fluid-filled tissue cysts over a period of months to years, with cysts developing in the liver and/or lung.

\section{Figure 1 Hydatid Tape Worm Life Cycle}

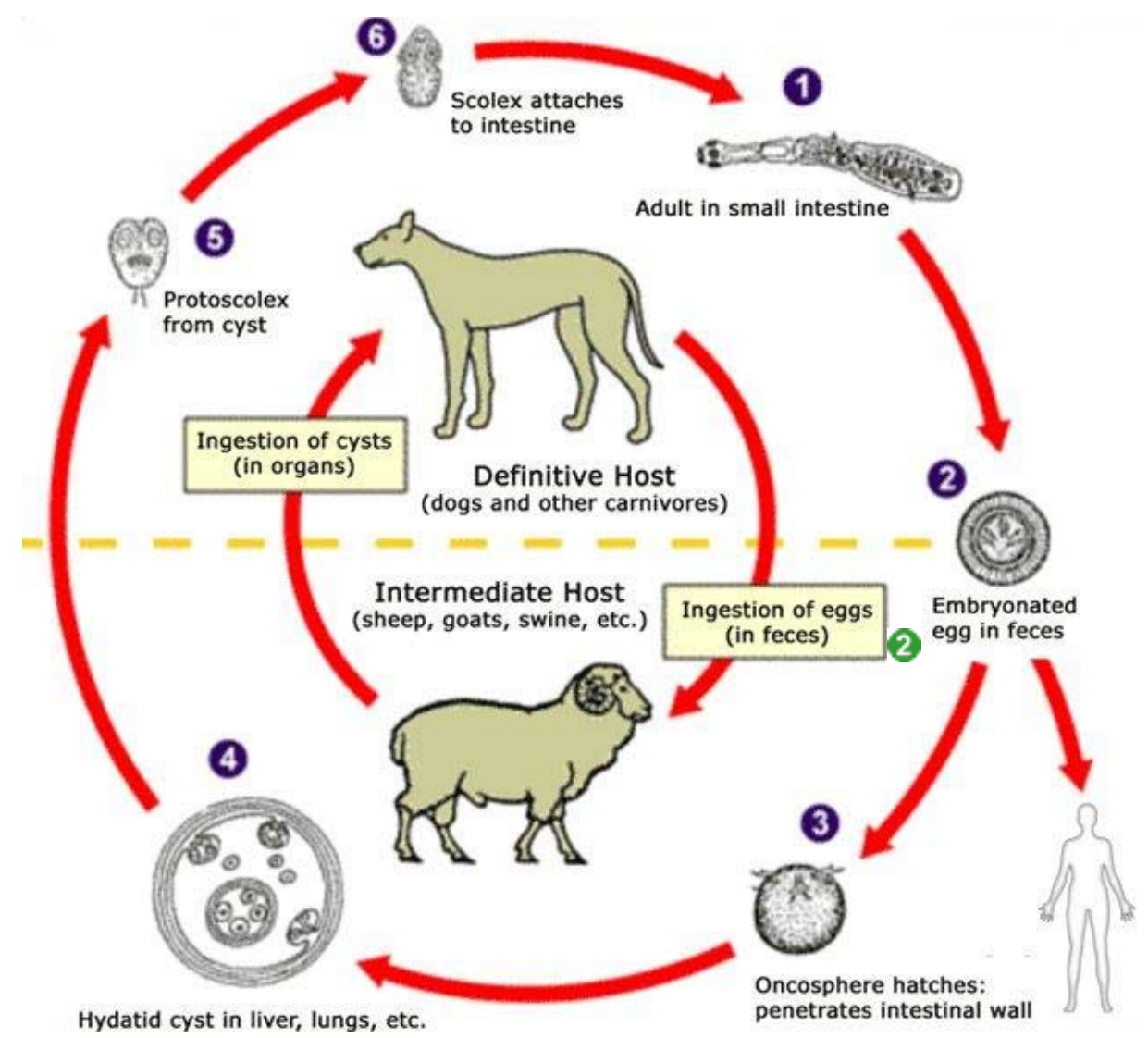

The adult Echinococcus granulosus (3 to $6 \mathrm{~mm}$ long) 1resides in the small bowel of the definitive hosts, dogs or other canids. Gravid proglottids release eggs 2 that are passed in the feces. After ingestion by a suitable intermediate host (under natural conditions: sheep, goat, swine, cattle, horses, camel), the egg hatches in the small bowel and releases an oncosphere 3 that penetrates the intestinal wall and migrates through the circulatory system into various organs, especially the liver and lungs. In these organs, the oncosphere develops into a cyst $\mathbf{4}$ that enlarges gradually, producing protoscolices and daughter cysts that fill the cyst interior. The definitive host becomes infected by ingesting the cyst-containing organs of the infected intermediate host. After ingestion, the protoscolices $\mathbf{5}$ evaginate, attach to the intestinal mucosa $\mathbf{6}$, and develop into adult stages $\mathbf{1}$ in 32 to 80 days. 2 Humans become infected by ingesting eggs. Figure 1 adapted from CDC. 


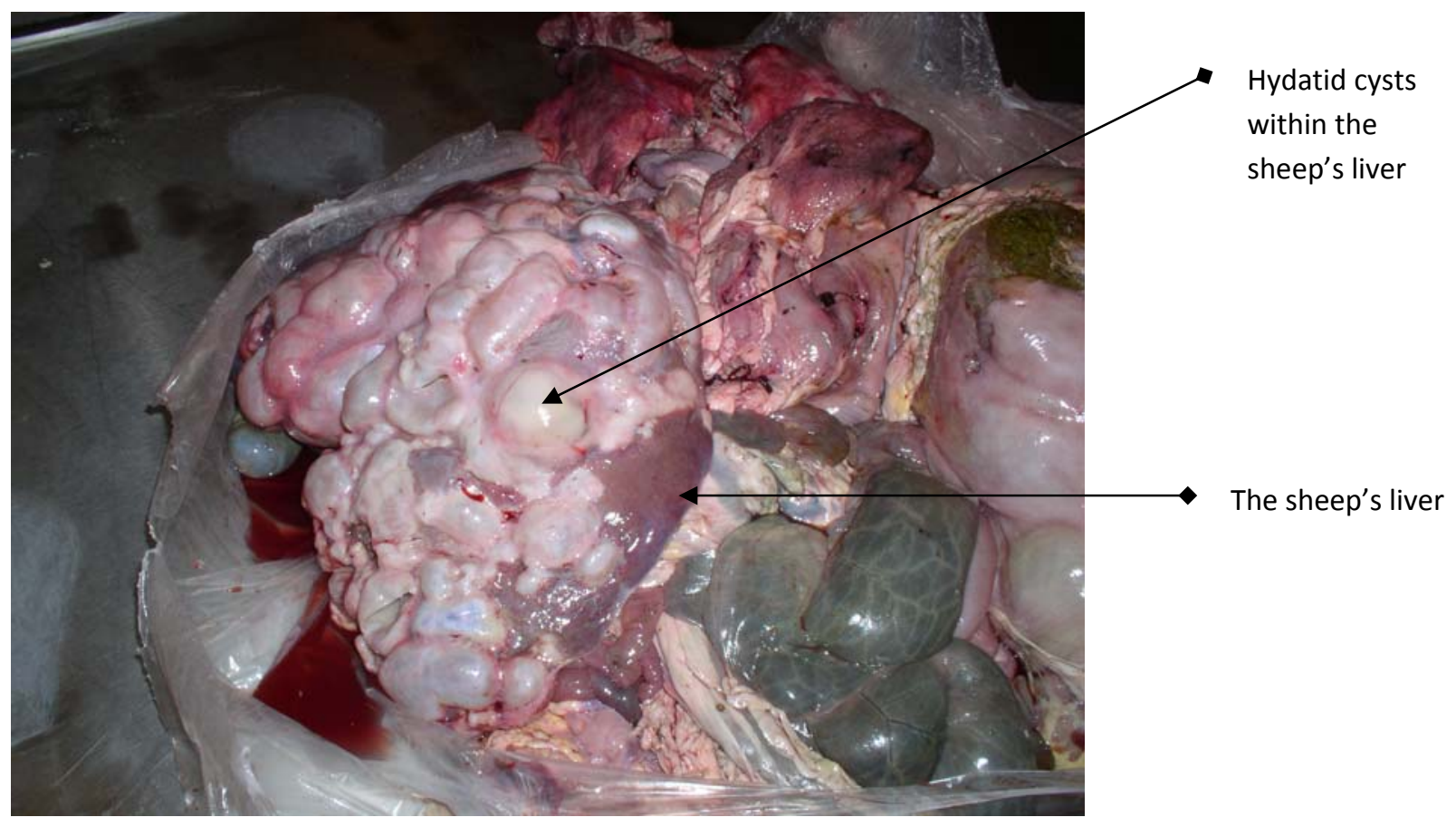

Figure 2: Numerous hydatid cysts in sheep liver, almost completely obliterating normal organ tissue

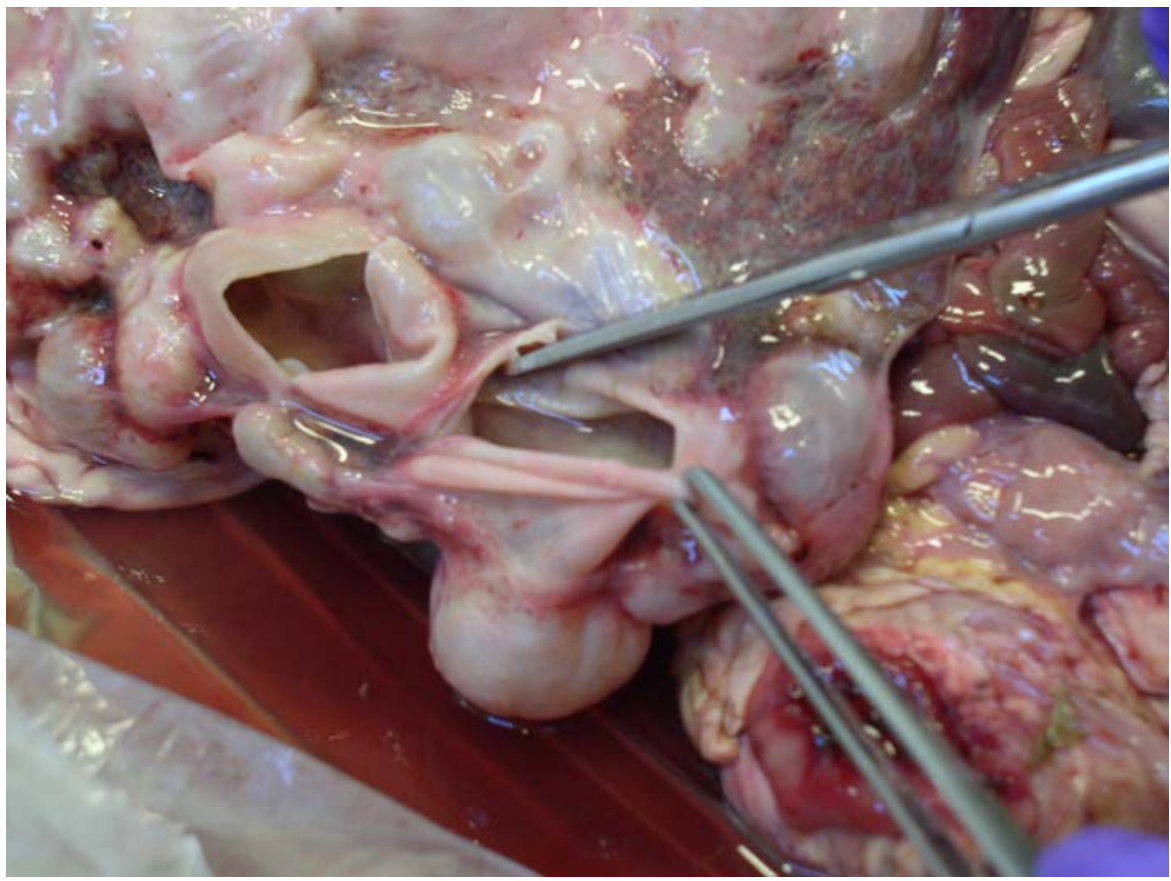

Figure 3: Sheep liver hydatid cysts opened up to illustrate fluid-filled cysts. 
Control is most effective when implemented on a community, area, or county-wide basis. It must include:

1. Deworming of all dogs that MAY have eaten uncooked sheep or deer viscera (internal organs).

a. This must be repeated at later times after any possible exposure. In some areas with a big problem with the parasite, programs have been set up in which dogs are dosed with praziquantel every 6 weeks

2. Disposal of dead sheep and sheep viscera, along with wild game, to prevent dog's access to eating it.

3. Elimination of stray dogs.

4. Control of all dogs to keep them from defecating in and around children's play areas.

5. Personal hygiene (hand washing) after handling or playing with dogs.

Not all deworming products are effective against tapeworms and not all that are available for the common tapeworms are effective against Echinococcus. At least three products are available which are highly effective against Echinococcus and they are very safe for use in dogs. One of these products should be used on any dog that has eaten raw sheep or wild game viscera. For dogs which may continue to have periodic exposure to sheep carcasses, consult with your veterinarian and plan a routine deworming program for as often as once every 4 to 6 weeks. The three products which have been shown to be effective are:

1. $\quad$ DRONCIT $^{\circledR}$ for dogs (from Bayer Animal Health ): A prescription product available as an injection (subcutaneous or intramuscular) or tablet. The active ingredient is praziquantel. The label indicates usage against Echinococcus as well as other common tapeworms. There are formulations of praziquantel that can be purchased over the counter without a prescription. Be sure to read and follow the label instructions carefully. Obtain an accurate weight on your dog prior to dosing with an over the counter product.

2. DRONTAL PLUS ${ }^{\circledR}$ chewable tablets or pills for dogs (Bayer Animal Health): A prescription product contains praziquantal, pyrantel pamoate, and febental so is effective against tapeworms including Echinococcus granulosus, hookworms, and ascarids

3. CESTEX $^{\circledR}$ (from Pfizer Animal Health): A prescription product available as a tablet. The active ingredient is epsiprantel, which is very closely related chemically to praziquantel. The label only indicates usage for the common tapeworms but research has shown it to be highly effective against the Echinococcus tapeworm. $^{123}$

In the past, repeated deworming has not been strongly encouraged by some because of the fear it would remove the emphasis from the other control measures and also give a false sense of security. However, the products now available are much more effective against Echinococcus than those of 20 years ago. Greater emphasis should be given to their routine and continued use and we should be grateful for the availability of more than one product. The other aspects of a community control program must still be emphasized and implemented. But families who own dogs should know that they can implement a control program of their own to give them a reasonable degree of security against hydatid disease, even if others in the community are not complying with the total program.

\footnotetext{
1 British Veterinary Journal (1989)145:384

2 Research in Veterinary Science (1990) 49:378-379

3 Research in Veterinary Science (1991) 51:332-334
}

Utah State University is committed to providing an environment free from harassment and other forms of illegal discrimination based on race, color, religion, sex, national origin, age (40 and older), disability, and veteran's status. USU's policy also prohibits discrimination on the basis of sexual orientation in employment and academic related practices and decisions. Utah State University employees and students cannot, because of race, color, religion, sex, national origin, age, disability, or veteran's status, refuse to hire; discharge; promote; demote; terminate; discriminate in compensation; or discriminate regarding terms, privileges, or conditions of employment, against any person otherwise qualified. Employees and students also cannot discriminate in the classroom, residence halls, or in on/off campus, USU-sponsored events and activities.

This publication is issued in furtherance of Cooperative Extension work, acts of May 8 and June 30, 1914, in cooperation with the U.S. Department of Agriculture, Noelle E. Cockett, Vice President for Extension and Agriculture, Utah State University. 